\title{
Gaming Disorder among Medical College Students during COVID-19 Pandemic Lockdown Shrestha MV, ${ }^{1}$ Manandhar $\mathrm{N}^{1}{ }^{1}$ Sharma SC, ${ }^{2}$ Joshi SK ${ }^{1}$
}

${ }^{1}$ Department of Community Medicine,

${ }^{2}$ Department of Psychiatry

Kathmandu Medical College,

Sinamangal, Kathmandu, Nepal.

\section{Corresponding Author}

Marina Vaidya Shrestha

Department of Community Medicine,

Kathmandu Medical College,

Sinamangal, Kathmandu, Nepal.

E-mail: merinavs@gmail.com

\section{Citation}

Shrestha MV, Manandhar N, Sharma SC, Joshi SK. Gaming Disorder among Medical College Students during COVID-19 Pandemic Lockdown. Kathmand Univ Med J. 2020;COVID-19 Special Issue 70(2):4852.

\section{ABSTRACT}

\section{Background}

The frequent lockdown in Nepal during COVID-19 pandemic had brought various kinds of complexities such as stress among college students. This situation had created uncertainty of future academic career of undergraduate students in medical colleges. Some previously published literature showed gaming as a coping mechanism against stress.

\section{Objective}

To assess the gaming behavior of Medical college students during lockdown in COVID-19 pandemic.

\section{Method}

A cross-sectional study was conducted during lockdown period of July to August 2020. A total of 412 college students were enrolled. Online Google forms were shared to all the eligible students through email, viber and messenger with the help of class representative. Collected data were analyzed in SPSS version 20.0.

\section{Result}

The prevalence of gaming disorder was $8.5 \%$ among 260 internet gaming users. About $69.2 \%$ of the participants reported that their gaming behavior had increased due to stress of COVID-19 pandemic. Gender and spending more time online per day showed significant associations with greater scores on the internet gaming disorder.

\section{Conclusion}

During lockdown period of COVID-19 pandemic, the gaming behavior of medical college students has increased.

\section{KEY WORDS}

COVID-19, Gaming disorder, Prevalence, Stress, Students 


\section{INTRODUCTION}

Gaming disorder (GD) is characterized by "a pattern of persistent or recurrent gaming behavior (also referred to as digital gaming or video-gaming), that may be primarily conducted over the Internet (online) or primarily conducted not on the Internet." ${ }^{1}$ Because of advanced technology, gaming devices are easily available in smart-phones, tablets or gaming consoles at affordable price and thus have made gaming more engaging, attractive and accessible. ${ }^{2}$ Playing digital games among adolescents and young adults has increased as a leisure activity. ${ }^{3}$ Although gaming is considered as harmless activity, in certain population adverse consequences engaging in this behavior is noticed. ${ }^{4}$ Gaming could be harmful to physical and mental well-being and may also promote negative behaviors such as smoking and aggression. ${ }^{5,6}$ Gaming disorder has been included as a diagnosable mental disorder in the recent revision of Classification of Diseases (ICD) 11 by the World Health Organization. ${ }^{7}$ The world is currently experiencing the COVID-19 pandemic. ${ }^{8}$ The fear of acquiring the infection, idea of getting quarantined, restrictions on movements, and social distancing could have an adverse impact on the mental health during the times of epidemics. ${ }^{9}$ Most of the students are likely to have experienced such a stressful situation for the first time in their lives. Gaming has been recognized as a coping mechanism against stress in the previously published literature. ${ }^{10}$ Hence this study aimed to assess the gaming behavior of college students and its association with stress due to COVID-19 pandemic.

\section{METHODS}

This was an internet-based, cross-sectional analytical online study. The study was conducted during July - August 2020. The study participants were undergraduate students pursuing their degree course in clinical health sciences (MBBS, Dental and Nursing).

The sample size was calculated using the formula:

$n=Z^{2} p(1-p) / d^{2}$ where,

$\mathrm{n}=$ required sample size

$z=$ level of confidence according to the standard normal distribution (for a level of confidence of $95 \%, z=1.96$ )

$\mathrm{p}=$ prevalence of $\mathrm{GD}=3.6 \%=0.036$ (Gaming disorder among medical college students from India) ${ }^{11}$

$d=$ tolerated margin of error. Since $p$ is $<0.1, d=p / 2$ or $0.036 / 2=0.018$

$\mathrm{n}=(1.96)^{2} 0.036(1-0.036) /(0.018)^{2}=411.47 \approx 412$

The main instrument to collect data was online questionnaire using Google forms. The developed draft survey instrument was distributed to faculty members to assess its validity and readability before pretesting among 10 randomly selected undergraduate students for relevance, clarity, and acceptability. Changes were made as required before the final questionnaire survey was distributed to the research participants.

The study questionnaire consisted of the following three parts: a semi-structured questionnaire to assess the socio demographic profile. Patient Health Questionnaire (PHQ) 9 and Generalized Anxiety Disorder (GAD) 7 scales and Internet Gaming Disorder Short Form-9 (IGDSF) were used for the measurement of depression and anxiety; respectively scores of each respondent were calculated by summing up the correct responses.

The PHQ-9 is a self report based tool, which scores each of the nine Diagnostic and Statistical Manual of Mental Disorder (DSM)-IV major depression criteria on a four point Likert scale from " 0 " (not at all) to " 3 " (nearly every day). The GAD-7 is a self rated scale used as a screening tool which consists of seven items also scored on a four point Likert scale from 0 (not at all) to 3 (nearly every day). PHQ-9 and GAD-7 have well established psychometric properties. ${ }^{12,13}$ The IGDS9-SF is a one-dimensional tool comprising of nine items, each reflecting one DSM-5 criteria for IGD. The psychometric properties of this instrument have been well-established. ${ }^{14}$ Those who did not respond were sent up to three reminders. These reminders were sent at a gap of 3 days. The study included undergraduate students studying at different Medical College in Nepal. Health care professionals, Interns and Postgraduate students were excluded from the study.

Ethical clearance was obtained from Institutional Review Committee (IRC of Kathmandu Medical College) prior to the start of study. Questionnaire did not contain any identification details of the students and confidentiality was strictly maintained throughout the study. Upon clicking on the link in Google form, the first page assured the confidentiality of data, informed about objectives and stated that the participation was purely voluntary. The participant's consent to participate in the study was implied when they clicked on the 'next' button to answer the questionnaire, and they had complete freedom either to decline or answer the questionnaire.

The data were compiled in Excel file and analyzed using the Statistical Package for the Social Sciences software (SPSS) 20. The correlation analysis (Pearson's correlation) and Independent $t$-test was applied. A $p$ value of $<0.05$ was considered statistically significant for all the tests.

\section{RESULTS}

Out of 412 students, only 377 Medical college students participated in the study indicating $91.50 \%$ response rate. The mean age of the participants was 20.85 years. Out of total participants $52.3 \%$ were females. Most of the students $(87.5 \%)$ were living with their family during this pandemic lockdown period. The areas of residence for most of them 
(48.3\%) were with in Kathmandu Valley. They believed in Hinduism (91.2\%). Almost $36.9 \%$ of students father were highly educated (post graduated) involved as employee (51.7\%) while mothers as housewives (63.7\%) (Table 1).

A total of 260 (69\%) out of 377 participants reported Table 1. Socio-demographic characteristics of respondents $(n=377)$.

\begin{tabular}{|c|c|}
\hline Variables & N (\%) \\
\hline Age & $20.85 \pm 1.75$ \\
\hline \multicolumn{2}{|l|}{ Gender } \\
\hline Male & $180(47.7)$ \\
\hline Female & $197(52.3)$ \\
\hline \multicolumn{2}{|l|}{ Area of residence } \\
\hline Inside Kathmandu Valley & $182(48.3)$ \\
\hline Outside Kathmandu Valley & $140(37.1)$ \\
\hline Outside country & $55(14.6)$ \\
\hline \multicolumn{2}{|l|}{ Current living arrangement } \\
\hline Alone & $25(6.6)$ \\
\hline Family & $330(87.6)$ \\
\hline Friends & $22(5.8)$ \\
\hline
\end{tabular}

playing internet games. A positive finding of internet gaming disorder (IGD) was found for 22 out of the 260 study participants. Thus, the prevalence of IGD was $8.5 \%$ in the present study sample. Most of the participants (65.8\%) in the study were using internet gaming since few years back and mode of internet gaming was smart phone 211 (81.2\%). Out of total participants $40 \%$ spend one to two hours on internet gaming in a day.

About $69.2 \%$ of the participants reported that their gaming behavior had increased due to stress of COVID-19. Further, 85\% participants reported an increase gaming help in combating stress and $86.5 \%$ reported that they prefer Internet gaming to cope with stress (Table 2).

Subsequently, Pearson's correlation and Independent t-test were conducted among the group of gamers to examine relationship and correlates of IGD. There was a significant correlation observed between the IGD score and time spent online per day $(r=0.442, P=0.001)$, Patient health questionnaire (PHQ-9) score $(r=0.434, \mathrm{P}<0.001)$ and Generalized Anxiety disorder (GAD) score ( $r=0.388$, $P<0.001$ ) representing the depressive symptom severity among the participants (Table 3 ).

The results of independent t-test showed gender and gaming hours to be associated with significantly greater IGD scores. However, there was no statistically significant relation with current living arrangements and gaming help in combating stress (Table 4).

\section{DISCUSSION}

The current study explored the gaming behavior among medical college students in the context of COVID-19 in Nepal. The results showed that playing digital games was a
Table 2. Status of Internet Gaming

\begin{tabular}{|c|c|}
\hline Variables & N (\%) \\
\hline \multicolumn{2}{|c|}{ Use of internet games ( $N=377$ ) } \\
\hline Yes & $260(69.0)$ \\
\hline No & $117(31.0)$ \\
\hline \multicolumn{2}{|c|}{ Start of internet gaming $(\mathrm{N}=\mathbf{2 6 0})$} \\
\hline Just before lockdown & $15(5.8)$ \\
\hline During lockdown & $74(28.5)$ \\
\hline Few years back & $15(5.7)$ \\
\hline \multicolumn{2}{|l|}{ Mode of internet gaming } \\
\hline Computer & $9(3.5)$ \\
\hline Laptop & $40(15.3)$ \\
\hline Smart phones & $211(81.2)$ \\
\hline \multicolumn{2}{|l|}{ Time spent on gaming } \\
\hline$<1$ hour & $95(36.6)$ \\
\hline $1-2$ hours & $104(40.0)$ \\
\hline 3-4 hours & $31(11.9)$ \\
\hline$>4$ hours & $30(11.5)$ \\
\hline \multicolumn{2}{|c|}{ Gaming has increased due to stress of COVID-19 } \\
\hline Yes & $221(85.0)$ \\
\hline No & $80(15.0)$ \\
\hline \multicolumn{2}{|c|}{ Prefer Gaming to cope with stress } \\
\hline Yes & $225(86.5)$ \\
\hline No & $39(13.5)$ \\
\hline \multicolumn{2}{|c|}{ Gaming help in Combating stress } \\
\hline Yes & $221(85.0)$ \\
\hline No & $39(15.0)$ \\
\hline IGD Score & $16.10 \pm 5.47$ \\
\hline PHQ-9 score & $7.02 \pm 6.16$ \\
\hline GAD Score & $6.1 \pm 5.3$ \\
\hline
\end{tabular}

Table 3. Correlation between Study variables and Internet gaming disorder (IGD) scale scores $(n=260)$.

\begin{tabular}{ll|}
\hline Study Variables & Pearson's correlation of IGD (P value) \\
\hline Age & $0.001(0.9)$ \\
\hline Time spent on gaming & $0.442^{* *}(<0.001)$ \\
\hline PHQ-9 score & $0.434^{* *}(<0.001)$ \\
\hline GAD score & $0.388^{* *}(<0.001)$ \\
\hline$* P<0.01$, highly significant &
\end{tabular}

relatively common activity among medical college students during lockdown period. However, relatively; a small proportion of the total study sample (8.5\%) met at least five out of the nine criteria needed for the diagnosis of IGD.

The prevalence of $8.5 \%$ reported in the present study was obtained by applying the Internet Gaming Disorder Scale Short-Form (IGDS9-SF) based on the nine criteria of IGD. This was higher as compared to study done by Singh et al. (3.6\%), Yu (5.9\%), Undavalli (3.5\%) and Wu et al. (2\%), a community based survey but was lower 
Table 4. Relationship between study variables and IGD-Score $(n=260)$

\begin{tabular}{|c|c|c|}
\hline Variables & IGD-score & $P$ value \\
\hline \multicolumn{3}{|l|}{ Gender } \\
\hline Male & $16.84 \pm 5.63$ & $0.02 * *$ \\
\hline Female & $15.26 \pm 5.18$ & \\
\hline \multicolumn{3}{|c|}{ Current living arrangements } \\
\hline Alone & $16.16 \pm 6.4$ & 0.96 \\
\hline Family/Friends & $16.09 \pm 5.4$ & \\
\hline \multicolumn{3}{|c|}{ Time spent on gaming } \\
\hline Short hours & $14.18 \pm 4.5$ & $<0.001 * *$ \\
\hline Long hours & $17.40 \pm 5.6$ & \\
\hline \multicolumn{3}{|c|}{ Gaming increase due to stress of COVID-19 } \\
\hline Yes & $17.04 \pm 5.6$ & $<0.01^{* *}$ \\
\hline No & $13.9 \pm 4.3$ & \\
\hline \multicolumn{3}{|c|}{ Gaming as method to cope with stress } \\
\hline Yes & $15.77 \pm 5.3$ & $0.016^{*}$ \\
\hline No & $18.17 \pm 6.0$ & \\
\hline \multicolumn{3}{|c|}{ Gaming help in combating stress } \\
\hline Yes & $16.27 \pm 5.4$ & 0.214 \\
\hline No & $15.07 \pm 5.6$ & \\
\hline
\end{tabular}

than the study of Balhara (14.84\%). ${ }^{11,15-18}$ Interestingly, the prevalence of gaming disorder has been reported to vary widely from $0.7 \%$ to $27.5 \%$ across studies. ${ }^{19}$ The variation in prevalence of IGD was likely to be due to the methodological differences applied in various studies, such as use of different assessment tools, cutoff scores, study sample characteristics, and survey methods employed for data collection.

More than half of the participants reported increased gaming behavior during the lockdown period. They also believed that gaming helped in managing stress related to COVID-19 pandemic. Similar finding was revealed at study conducted by Balhara. ${ }^{18}$ The fear of acquiring the infection, idea of getting quarantined, restrictions placed on movements, and physical distancing could have an adverse impact on the mental health during the times of

\section{REFERENCES}

1. WHO. Gaming disorder [Internet]. 2019 [cited on 2019 Nov 6]. Available from: https://www.who.int/westernpacific/news/q-adetail/gaming

2. Faust KA, Prochaska JJ. Internet gaming disorder: A sign of the times, or time for our attention? [Internet]. Addict Behav. 2018; 77:272. [cited 2020 July 20]. Available from: https://escholarship.org/ content/qt2bg1x9n5/qt2bg1x9n5.pdf

3. Fiona M. Brooks, Kayleigh L. Chester, Nigel C. Smeeton, et al. Video gaming in adolescence: factors associated with leisure time use. Journal of Youth Studies. 2016;19:36-54. DOI: 10.1080/13676261.2015.1048200

4. Saunders JB, Hao W, Long J, et al. Gaming disorder: Its delineation as pandemics. The uncertainty about the adverse impact of this situation on their future academic and carrier prospects, besides other concerns, makes college students particularly vulnerable to stress during the COVID-19 pandemic.

Gender and spending more time online per day showed significant associations with greater scores on the IGDS9-SF. Similar findings were found in study Singh et al. ${ }^{11}$ However, this study failed to show a significant association with the IGDS9-SF scores and current living arrangements and age. In contrary, study done by Wu in China showed no statistical significance among gender and age. ${ }^{17}$ This suggests that both males and females are equally vulnerable to develop IGD. Further, it was observed that the greater duration of gaming time per day spent online was a significant independent factor associated with greater scores on the IGDS9-SF. Similar findings were found in study conducted in Korea by Yu. ${ }^{15}$

Further, the present study showed higher PHQ-9 scores and GAD score significantly associated with greater scores on the IGD, suggestive of higher risk of having IGD with increasing depressive symptom severity. The study conducted by Singh et al. also revealed the same findings. ${ }^{11}$

\section{CONCLUSION}

Majority of medical college students had increased their gaming behavior during COVID-19 pandemic lockdown which was associated with stress and the belief that gaming helps to cope with stress. This study strongly suggests that IGD among medical students in Nepal is an important emerging mental health condition with negative impact of excessive gaming on the physical, psychosocial determinants of health in individuals.

\section{ACKNOWLEDGEMENTS}

Authors would like to thank the study participants, without whom the study would not been possible.

an important condition for diagnosis, management, and prevention. $J$ Behav Addict. 2017;6:271-9. Doi: 10.1556/2006.6.2017.039

5. Dejan S, Ana $Ð$, Pal Singh BY, et al. Assessing the symptoms of Internet Gaming Disorder among college/university students: An international validation study of a self-report. Psihologija. 2020;53:43-63. Doi: https://doi.org/10.2298/

6. Anderson CA, Shibuya A, Ihori N, et al. Violent video game effects on aggression, empathy, and prosocial behavior in eastern and western countries: A meta-analytic review. Psychol Bull. 2010 Mar;136(2):15173. Doi: $10.1037 / a 0018251$

7. WHO. International classification of disease 11revision. The global 
standard for diagnostic health information [Internet]. 2020 [cited 2020 July 28]. Available from: https://www.who.int/classifications/ icd/en/bluebook.pdf

8. WHO. Situations update COVID-19.WHO country office for Nepal [Internet]. 2020 April [cited 2020 July 28]. Available from: https:// www.who.int/nepal/news/detail/09-09-2020-who-nepal-situationupdate

9. da Silva AG, Miranda DM, Diaz AP, et al. Mental health: Why it still matters in the midst of a pandemic [Internet]. Braz J Psychiatry. 2020 [cited 2020 July 28]. DOI: http://dx.doi.org/10.1590/1516-44462020-0009

10. Canale N, Marino C, Griffiths MD, et al. The association between problematic online gaming and perceived stress: The moderating effect of psychological resilience. J Behav Addict. 2019; 8:174-80. DOI: 10.1556/2006.8.2019.01

11. Singh S, Dahiya N, Singh $A B$, et al. Gaming disorder among medical college students from India: Exploring the pattern and correlates. Industrial Psychiatry Journal. 2019 Jan-Jun; 28(1): 107-114. Doi: 10.4103/ipj.ipj_96_18

12. Rutter LA, Brown TA. Psychometric Properties of the Generalized Anxiety Disorder Scale-7 (GAD-7) in outpatients with anxiety and mood disorders. J Psychopathol Behav Assess. 2017;39:140-6. Doi: 10.1007/s10862-016-9571-9

13. Kroenke K, Spitzer RL, Williams JB. The PHQ-9: Validity of a brief depression severity measure. J Gen Intern Med. 2001;16(9):606-13. Doi: 10.1046/j.1525-1497.2001.016009606.x
14. Pontes HM, Griffiths MD. Measuring DSM-5 internet gaming disorder: Development and validation of a short psychometric scale. Comput Hum Behav. 2015;45:137-43. DOI: https://doi.org/10.1016/j. chb.2014.12.006

15. Yu H, Cho J. Prevalence of Internet Gaming Disorder among Korean Adolescents and Associations with Non-psychotic Psychological Symptoms, and Physical Aggression. Am J Health Behav. 2016;40(6):705-716. Doi: 10.5993/AJHB.40.6.3.

16. Undavalli VK, Rani GS, Jonnalagadda RK. Prevalence of internet gaming disorder in India: a technological hazard among adolescents. Int J Community Med Public Health. 2020 Feb; 7(2):688-693. DOI: http://dx.doi.org/10.18203/2394-6040.ijcmph20200450

17. Wu AMS, Chen JH, Tong K, et al. Prevalence and associated factors of Internet gaming disorder among community dwelling adults in Macao, China. Journal of Behavioral Addictions. 2018;7(1):62-69. DOI: 10.1556/2006.7.2018.12

18. Balhara YP, Kattula D, Singh S, et al. Impact of lockdown following COVID-19 on the gaming behavior of college students. Indian J Public Health. 2020;64:S172-6. DOI:10.4103/ijph.IJPH_465_20.

19. Mihara S, Higuchi S. Cross-sectional and longitudinal epidemiological studies of Internet gaming disorder: A systematic review of the literature. Psychiatry Clin Neurosci. 2017; 71:425-44. Available from: https://onlinelibrary.wiley.com/doi/full/10.1111/pcn.12532 